\title{
Produksi Podcast Pada Program "OSIS (Obrolan Seru Inspirasi Siswa) Studi Kasus di SMK Taruna Terpadu 1
}

\author{
Nadya Zakiroh ${ }^{1}$, Fatimah $^{2}$, Dedy Zebua ${ }^{3}$ \\ ${ }^{1,2,3}$ Sekolah Tinggi Ilmu Komunikasi Indonesia Maju \\ Email correspondent: nicojoranof@gmail.com
}

\begin{abstract}
Abstrak
Perkembangan podcast yang semakin merajai sebagai salah satu konten audio masa kini membuat banyak platform berlomba-lomba untuk mendapatkan jumlah pengguna terbanyak, dan dengan banyaknya platform tersebut yang memberikan akses kemudahan bagi para pendengar untuk mendapatkan pengalaman terbaik. Beberapa platform yang dapat diakses adalah Spotify, Apple Podcast, Google Podcast, Anchor, Soundcloud dan masih banyak lainnya. Tujuan Penelitian ini adalah untuk mengenai analisis pada "Proses Produksi Podcast pada Program OSIS (Obrolan Seru Inspirasi Siswa) Studi Kasus di SMK Taruna Terpadu 1. Penelitian ini termasuk kedalam penelitian kualitatif deskriptif. Penelitian ini menjelaskan tentang pembahasan mengenai sebuah fenomena secara mendalam. Pengambilan data menggunakan wawancara. Hasil Penelitian ini adalah dengan menggunakan strategi produksi Podcast Pada Program "OSIS (Obrolan Seru Inspirasi Siswa) Studi Kasus di SMK Taruna Terpadu 1 dengan menggunakan strategi pra produksi, produksi dan pasca produksi sehingga podcast OSIS (Obrolan Seru Inspirasi Siswa) Studi Kasus di SMK Taruna Terpadu 1 mempunyai pendengar baik dari SMK Taruna Terpadu 1.KesimpulanProduksi Podcast di SMK Taruna Terpadu 1diproduksi dengan professional baik dengan sumberdaya manusia yang handal dibidang broadcasting. Podcast di SMK Taruna Terpadu 1 diproduksi dengan pra produski dan pasca produksi sehingga menghasilkan podcast yang baik.
\end{abstract}

Kata kunci: podcast,program, smk taruna terpadu 1

\begin{abstract}
The development of podcasts that increasingly dominates as one of today's audio content makes many platforms vying to get the largest number of users, and with so many platforms providing easy access for listeners to get the best experience. Some of the platforms that can be accessed are Spotify, Apple Podcasts, Google Podcasts, Anchor, Soundcloud, and many others. The purpose of this study is to analyze the "Podcast Production Process in the OSIS (Student Inspirational Chat) Program. This study describes the discussion of a phenomenon in depth. Collecting data using interviews. The result of this research is to use a Podcast production strategy in the "OSIS (Student Inspirational Fun Chat) Case Study Program at SMK Taruna Terpadu 1 by using pre-production, production, and post-production strategies so that the OSIS podcast (Student Inspiration Fun Chat) Case Study at SMK Taruna Terpadu 1 has good listeners from SMK Taruna Terpadu 1. Conclusion Podcast production at SMK Taruna Terpadu 1 is professionally produced with reliable human resources in the field of broadcasting. Podcasts at SMK Taruna Terpadu 1 are produced by pre, production, and post-production to produce good podcasts.
\end{abstract}

Keywords: podcast, program, smk taruna terpadu 1 


\section{Pendahuluan}

Bahkan melihat popularitas podcast di Indonesia yang semakin meroket, Pegipegi sebagai perusahaan Online Travel Agent (OTA) kini menjadi pionir yang membuat podcast seputar traveling. Sudah ada sembilan episode podcast yang diunggah oleh Pegipegi ke kanal Ngobrol Pegipegi di Spotify dan Apple iTunes.

Perkembangan podcast yang semakin merajai sebagai salah satu konten audio masa kini membuat banyak platform berlomba-lomba untuk mendapatkan jumlah pengguna terbanyak, dan dengan banyaknya platform tersebut yang memberikan akses kemudahan bagi para pendengar untuk mendapatkan pengalaman terbaik. Beberapa platform yang dapat diakses adalah Spotify, Apple Podcast, Google Podcast, Anchor, Soundcloud dan masih banyak lainnya. ${ }^{15}$

Bagi layanan streaming music yang populer saat ini seperti Spotify misalnya, podcast menjadi salah satu daya tarik tersendiri bagi para penggunanya. Saat ini salah satu platform yang paling memiliki banyak pendengar untuk kategori podcast adalah Spotify, sebelum Spotify awalnya banyak podcaster (panggilan bagi pembuat podcast) yang lebih popular di Soundcloud, namun setelah Spotify menambahkan fitur podcast banyak para podcaster yang kemudian berpindah ke platform tersebut. Kini, semakin hari pendengar podcast terus bertambah. Sampai-sampai membuat jumlah pengguna Spotify melonjak karenanya. ${ }^{15}$

Dalam laporan Q4 2020, disebutkan kalau jumlah pelanggan Spotify tembus 271 juta pengguna di Indonesia. Atau naik 31\% dibanding tahun lalu. Dengan jumlah tersebut membuat Spotify mampu merekuh pendapatan US\$ 2 miliar atau kisaran Rp 27,3 triliun. Ini naik 24\% dibandingkan tahun lalu. Sepanjang tahun lalu, layanan podcast Spotify tumbuh 200\%, dan sebanyak $16 \%$ pengguna aktif bulanannya adalah pendengar podcast

Pada platform Spotify, podcast memiliki berbagai macam kategori. Mulai dari kisah, horror \& kriminalitas, berita \& politik, olahraga \& kreasi, masyarakat \& budaya, pendidikan, bisnis \& teknologi, gaya hidup \& kesehatan, keluarga, games, komedi, music, seni dan juga hiburan.

Berdasarkan peringkat Top Podcast Spotify Indonesia pada tanggal 25 Juli 2020, Podcast dengan genre sastra yaitu Rintik Sedu masih menjadi salah satu yang paling banyak diminati oleh para pendengar. Rintik Sedu merupakan nama pena dari penulis yaitu Tsana, podcast ini membahas banyak hal mulai dari kisah asmara hingga kehidupan sehari-hari. Suara merdu dari Tsana dengan kata-kata puitis yang mampu membawa perasaan dari para audiens, serta background music yang menenangkan menjadi hal favorit dari penggemar podcast sastra ini. Kemudian di peringkat kedua ada PODKESMAS dengan genre Komedi. PODKESMAS merupakan singkatan dari Podcast Kesehatan Masyarakat. Podcaster dalam program ini ada empat orang yang memiliki background sebagai komedian yaitu, Imam Darto, Omesh, Surya Dini, dan Angga Nggok. Selain itu mereka juga merupakan penyiar radio dan beberapa bahkan masih aktif hingga saat ini. Program PODKESMAS membahas banyak hal random yang pastinya penuh dengan komedi, sehingga dapat menjadi hiburan bagi para pendengarnya. Kemudian diperingkat ke empat diduduki oleh Do You See What I See yang dibawakan oleh Rizky Ardi Nugroho, dengan genre Horor. Podcast ini membahas banyak hal horror yang juga pernah dialami oleh para pendengar, dan genre horor termasuk salah satu jenis yang paling banyak diminati oleh para pendengar podcast tanah air.

Secara garis besar dapat disimpulkan bahwa para pendengar lebih menyukai ketiga genre tersebut, terutama komedi yang lebih banyak menempati posisi 7 besar Top Podcast Spotify Indonesia. Dalam platform spotify terdapat salah satu channel yang menarik perhatian penulis karena merupakan podcast milik sebuah Lembaga Pendidikan, yaitu SMK Taruna Terpadu 1. SMK Taruna Terpadu 1 merupakan salah satu sekolah terbesar di Kota Bogor yang beralamatkan di Jl. Raya Semplak, Salabenda Kec. Kemang, Kab.Bogor, Provinsi Jawa Barat. SMK Taruna Terpadu 1 merupakan Yayasan yang diketuai oleh Bapak Muztahidin Al-Ayubi ini, berdiri sejak tanggal 24 September 2002. SMK 
Taruna Terpadu 1 atau yang lebih dikenal dengan nama BOASH (Borcess Ashokal Hajar) ini memiliki sebuah sarana pendukung bagi siswa dan siswinya yang ingin terus berkembang aktif serta memiliki ketertarikan dalam mempelajari dunia broadcasting (penyiaran) yaitu dengan cara membangun Boash Media.

Boash Media merupakan sebuah wadah untuk siswa dan siswi berkreasi, belajar, dan berproses dalam segala bidang penyiaran. Di dalam Boash Media, siswa-siswi tidak hanya belajar mengenai teknik produksi video tetapi juga audio. Dengan begitu, pada tahun 2018 lahir-lah Podcast Boash Official pada platform Spotify. Program yang pertama kali di rilis pada channel tersebut yaitu Boash People, program ini dibawakan secara bergantian oleh para siswa-siswi yang ikut aktif dalam Boash Media. Program ini merupakan kegiatan untuk menyampaikan pesan dari para pendengar dengan tema yang telah ditentukan oleh sang podcaster setiap minggunya. Kemudian program Boash Dakwah yang membahas mengenai hal-hal religi termasuk membaca Al-Qur'an. Yang ke tiga ada program Boash Bercakap, program ini membahas mengenai kenangan ataupun pengalaman dari para siswa-siswi Boash selama di sekolah. Dan yang terakhir merupakan program yang di rilis pada Januari 2019 lalu, yaitu program OSIS (Obrolan Seru Inspirasi Siswa). Program ini membahas mengenai hal-hal random yang dikemas dengan informasi yang cukup menarik dan dengan pembawaan podcaster yang menyenangkan serta tentunya menginspirasi, salah satu episode yang menarik bagi peneliti adalah pembahasan mengenai 'tawuran'.

Hal ini tentunya sangat menarik bagi peneliti, karena sekolah memberikan sarana atau media bagi para siswa dan siswi untuk dapat lebih kreatif dengan mengasah kemampuan dan ketertarikan mereka dalam belajar tetang penyiaran dan tentunya agar para siswa-siswi juga bisa menyalurkan aspirasi serta memberikan inspirasi terhadap teman maupun orang banyak. Maka dari itu, berdasarkan latar belakang tersebut penulis ingin mengetahui tentang bagaimana tahapan proses produksi podcast pada program OSIS (Obrolan Seru Inspirasi Siswa) yang terdapat pada channel Boash Official sehingga layak untuk disiarkan kepada para pendengar setia yang ada di Spotify. ${ }^{13}$

Tujuan Penelitian ini adalah untuk mengenai analisis pada "Proses Produksi Podcast pada Program OSIS (Obrolan Seru Inspirasi Siswa) Studi Kasus di SMK Taruna Terpadu 1.

\section{Metode}

Penelitian ini termasuk kedalam penelitian kualitatif deskriptif. Penelitian ini menjelaskan tentang pembahasan mengenai sebuah fenomena secara mendalam. Menurut Burhan penelitian kualitatif merupakan suatu metode penelitian untuk mengeksplorasi dan memahami makna oleh sejumlah individu atau sekelompok orang yang dianggap berasal dari masalah. Data yang digunakan juga merupakan kata-kata deskriptif dan tidak berbentuk angka. Dalam penelitian ini lebih menekankan tentang persoalan kualitas data, bukan pada kuantitas data. Jenis peelitian ini juga memanfaatkan wawancara terbuka untuk dapat medalami tentang pandangan, perasaan, sikap dan perilaku terhadap individu atau kelompok. ${ }^{2}$ Dan semua data yang berhasil dikumpulkan dapat memungkinkan untuk menjadi sebuah kunci terhadap apa yang diteliti, dimana penelitian ini akan fokus pada mengembangkan pertanyaan-pertanyaan kepada subjek penelitian tesebut.

Dalam penelitian ini, peneliti menggunakan metode studi kasus guna memperoleh pengertian yang mendalam mengenai situasi dan makna dari subyek yang diteliti. Studi kasus adalah eksplorasi mendalam dari sistem terikat berdasarkan pengumpulan data yang luas. Kasus dapat berupa individu, program, kegiatan, sekolah, ruang kelas, atau kelompok. Setelah kasus didefinisikan dengan jelas, peneliti menyelidiki secara mendalam, biasanya menggunakan beberapa metode pengumpulan data, seperti wawancara, observasi lapangan, dan dokumentasi. ${ }^{6}$

Pada penelitian ini, peneliti akan menjabarkan tentang proses dan masalah yang dilalui dalam pembuatan podcast. Dengan melalui pendekatan ini maka peneliti akan menjabarkan hasil analisa 
secara deskriptif, yaitu secara sistematis, faktual, dan akurat tentang proses pembuatan podcast pada program OSIS (Obrolan Seru Inspirasi Siswa) di SMK Taruna Terpadu 1. Sebuah keunikan dari studi kasus adalah kemampuan untuk berhubungan sepenuhnya dengan berbagai jenis bukti, seperti dokumen, peralatan, wawancara, dan observasi ${ }^{14}$

Menurut Sugiono Sumber data penelitian dibedakan menjadi dua, yaitu sumber data primer dan sumber data sekunder. Dalam penelitian ini data yang digunakan adalah data yang bersifat primer dan sekunder ${ }^{12}$ :

\section{Sumber Data Primer}

Sumber data primer merupakan sumber data yang langsung memberikan data kepada pengumpul data. ${ }^{12}$ Data primer dapat berupa opini objek secara individual maupun kelompok, hasil observasi, kegiatan, dan juga hasil dari pengujian. Data utama dapat diperoleh melalui proses wawancara secara mendalam yang dilakukan dengan subjek penelitian yang kemudian dapat dilanjutkan dengan tahap penulisan dengan cara mendeskripsikannya melalui kata-kata. Wawancara secara mendalam dapat dilakukan untuk menggali informasi dari subjek penelitian mengenai proses produksi podcast. Salah satu elemen yang terpenting dalam melakukan proses wawancara adalah dengan menentukan terlebih dahulu subjek dan objek yang tepat dari penelitian. Data ini diperoleh dari hasil wawancara dengan editor yang melakukan proses produksi podcast pada pada program OSIS (Obrolan Seru Inspirasi Siswa) di SMK Taruna Terpadu 1.

\section{Sumber Data Sekunder}

Menurut Sugiono data sekunder adalah sumber data yang tidak langsung memberikan data kepada pengumpul data, misalnya melalui orang lain atau dokumen.. Sumber data sekunder ini peneliti dapatkan dari arsip dan dokumentasi yang dimiliki oleh SMK Taruna Terpadu $1 .{ }^{12}$

Salah satu metode yang paling penting dalam proses penelitian adalah Teknik dalam pengumpulan data. Karena dengan mengumpulkan data yang relevan akan mampu menghasilkan data yang memiliki kredibilitas yang tinggi. Serta tujuan utama dari penelitian adalah untuk mendapatkan data dan hasil yang relevan. Apabila terjadi kesalahan dalam metode pengumpulan data, maka akan mempengaruhi kredibilitas dari hasil penelitian dan tidak dapat dipertanggung jawabkan. Dengan demikian, peneliti meneggunakan 3 metode yaitu wawancara, observasi dan juga dokumentasi. ${ }^{9}$

\section{Hasil dan Pembahasan}

\section{Podcast Memiliki Perbedaan dengan Radio Konvensional}

Podcast dan radio memiliki kesamaan yaitu konten podcast audio memiliki sebagian karakteristik dari radio siaran, misalnya seperti sifatnya yang auditif dan mampu membangun imajinasi seseorang. Tetapi, konten podcast audio yang dimuat pada media online merupakan bagian dari medium interaktif, berbeda dengan materi dari siaran audio yang dimuat pada radio siaran konvensional ataupun radio online yang merupakan bagian dari medium linear. ${ }^{6}$ berikut ${ }^{8}$ :

Menurut Meisyanti perbedaan podcast dan radio konvesional terdapat pada komponen sebagai

\section{Music dan iklan}

Pada konten-konten podcast jarang memiliki iklan dan music (kecuali dalam kategori music), sedangkan radio konvensional biasanya terdapat banyak iklan dan selalu diselingi dengan music pada setiap segmentnya. 
Volume 13, No.02, Juli. 2021

\section{Akses}

Podcast dapat diakses melalui internet, sedangkan radio konvensional diakses dengan menggunakan frekuensi.

\section{Waktu pemutaran}

Podcast dapat diputar atau didengarkan kapan pun dan dimana pun, sedangkan radio memiliki jadwal siaran sendiri dan tidak dapat diputar ulang kembali.

\section{Topik pembahasan}

Jika podcast pembahasannya lebih spesifik dan dapat dipilih sesuai dengan kebutuhan dan keinginan dari pendengarnya saja, sedangkan radio konvensional biasanya memiliki pembahasan yang lebih luas dan mencakup banyak hal (tidak spesifik).

\section{Karakteristik dan Jenis-Jenis Podcast}

SMK Taruna Terpadu 1 atau yang lebih dikenal dengan istilah BORCESS (Bogor Center School) ini membangun sebuah wadah organisasi bagi para siswa dan siswi untuk dapat berkontribusi aktif dan menambah ilmu serta wawasan, bukan hanya tentang teori tetapi siswa-siswi yang tergabung dalam Boash Media ini juga langsung mempraktikan apa yang mereka pelajari dan terlibat langsung dalam proses produksi. Bukan hanya produksi tentang podcast tetapi juga pada proses produksi konten-konten lainnya seperti youtube, film pendek, music, dan lain sebagainya.

Seiring berjalannya waktu dan perkembangan zaman, teknologi semakin maju dan berkembang hingga bermunculan produk-produk dari media baru, seperti salah satunya adalah podcast. Podcast merupakan file audio digital yang diproduksi kemudian di publish (unggah) ke platform online untuk dapat di bagikan kembali kepada orang lain

\section{Proses Produksi Podcast pada Program OSIS (Obrolan Seru Inspirasi Siswa)}

Dalam tahapan produksi podcast tidak jauh berbeda SOP (Standar Operasional Prosedur) yang dijalankan dengan proses produksi siaran televisi maupun produksi radio. Yang berbeda hanya dalam penyajian dan software (perangkat lunak) editing-nya saja. Secara umum dalam mekanisme produksi program terdapat 3 (tiga) tahapan standart procedure (SOP) yaitu pra produksi, produksi, dan pasca produksi.

Membuat rencana siaran sama dengan membuat konsep acara yang dapat disajikan kepada pendengar. Tahapan-tahapan produksi dalam program radio terdiri dari pra produksi, produksi, dan pasca produksi. ${ }^{5}$

Berikut ini merupakan penjabaran dari tahap-tahap proses produksi yang telah dilakukan oleh tim Boash Media dalam proses produksi podcast.

\section{Pra Produksi}

Pada tahapan pra produksi dimulai dengan Hasil pembahasan pada proses produksi podcast pada program OSIS (Obrolan Seru Inspirasi Siswa) ini melalui banyak tahap. Salah satu alasan mengapa tim Boash Media memilih Spotify sebagai platform yang digunakan sebagai distributor podcast mereka, adalah karena Spotify menjadi salah satu aplikasi audio yang paling banyak memiliki pengunduh dengan total lebih dari 500 juta unduhan pada aplikasi Playstore di android. Hal ini menjadikan Spotify sebagai salah satu platform audio yang paling banyak diminati oleh masyarakat.

Dalam prosesnya anggota tim program OSIS tetap mengikuti SOP (Standar Operasional Prosedur) sebagai pedoman produksi konten podcast. SOP yang digunakan dalam proses produksi podcast Oini juga tidak memiliki banyak perbedaan dengan SOP produksi vidio, televisi maupun radio. ${ }^{11}$ 
Pada tahapan pra produksi yang pertama dilakukan oleh tim adalah dengan brainstorming ide, dengan cara mengumpulkan semua ide dari para anggota tim yang kemudian dicatat poin-poin apa yang akan diambil untuk pembahasan episode yang akan di produksi selanjutnya. Tidak lupa juga tim harus melakukan riset agar tidak ada kesalahan informasi yang diberikan, yang ditakutkan nantinya akan membuat dampak yang negatif. ${ }^{10}$ Kemudian dilanjutkan dengan pembuatan naskah yang dilakukan oleh penanggung jawab naskah yaitu script writer. Setelah itu sebelum masuk ke tahap produksi, tim juga menyiapkan peralatan yang akan digunakan untuk proses produksi.langkah pertama yaitu mencari ide yang kemudian dikembangkan menjadi sebuah konsep, dilanjutkan dengan melakukan riset, kemudian membuat rundown program, kalkulasi biaya, rencana lokasi, pelatan dan kru yang akan ikut serta terlibat dalam proses produksi. ${ }^{7}$

\section{Produksi}

Pada tahap produksi adalah tahap dalam eksekusi program, baik siaran secara langsung maupun rekaman. ${ }^{7}$ Dalam tahapan produksi podcast ini, tim Boash Media biasanya melakukan tahap recording di studio khusus yang sekolah bangun sebagai sarana dan fasilitas pendukung untuk berjalannya program acara yang di produksi oleh tim Boash Media.

Sebelum memulai produksi, pastinya harus ada peralatan yang disiapkan untuk keberlangsungan tahap produksi, agar planning dapat berjalan sesuai dengan apa yang diharapkan. Dan untuk peralatan yang digunakan dalam proses produksi podcast pada program OSIS (Obrolan Seru Inspirasi Siswa) ini juga merupakan fasilitas yang disediakan oleh pihak sekolah. Beberapa peralatan tersebut yaitu, microphone, speaker, headphone, kamera, tripod, komputer, mouse, dan properti-properti yang dibutuhkan lainnya.

\section{Pasca Produksi}

Ditahap yang terakhir yaitu proses pasca produksi, yaitu editing program, mulai dari offline, online, mixing dan mastering. ${ }^{7}$ Dalam tahapan pasca produksi program OSIS (Obrolan Seru Inspirasi Siswa) proses yang dilalui adalah tahap editing, evaluasi tim, publikasi dan juga promosi.

Sedangkan pada tahap produksi, yaitu proses recording audio. Sebelum podcaster melakukan tahap recording podcaster diharuskan terlebih dahulu membaca naskah yang sudah dibuat oleh script writer dan sudah menguasai materi. Maka dari itu sebelum proses recording podcaster sudah harus melakukan riset bersama tim terlebih dahulu di tahap pra produksi sebelum akhirnya melakukan take audio. Dan pada saat proses produksi tim produksi juga harus turut serta hadir untuk membantu jalannya proses recording serta mencegah terjadinya kendala pada alat-alat yang digunakan.

Dan yang terakhir di tahap Pasca Produksi, pada tahapan ini setelah podcaster melakukan proses recording hasil file audio kemudian di edit langsung oleh editor. Dalam tahap editing, editor hanya melakukan proses cut to cut saat terjadi kesalahan dalam pengucapan dari podcaster, menghilangkan noise yang masuk, serta menambahkan sedikit instrument dan juga backsound pendukung guna memberikan kesan santai dan tidak membosankan bagi para pendengar. Kemudian setelah proses editing selesai, tim akan memberikan evaluasi terlebih dahulu, apakah masih ada yang perlu diperbaiki ataukah ada kata-kata yang mungkin kurang tepat di ucapkan oleh sang podcaster sehingga masih harus perlu dirubah kembali sebelum akhirnya menjadi konsumsi publik. Tahap evaluasi ini dilakukan guna mengurangi kecelakaan produksi, yang dapat menyebabkan kesalahan pemberian informasi, apalagi podcast OSIS ini termasuk kedalam genre informasi dan Edukasi. Maka dari itu, ada banyak hal yang tentunya harus sangat diperhatikan agar tidak menimbulkan hal-hal yang tidak diinginkan, dan guna memberikan informasi dan edukasi yang sesuai bagi para pendengar, khususnya siswa dan siswi SMK Taruna Terpadu 1. 
Dan yang terakhir berdasarkan hasil evaluasi dari pendengar podcast OSIS, ada salah satu hal yang masih perlu ditingkatkan lagi dari program OSIS tersebut, yaitu kualitas suara. Sejauh ini kualitas suara dari program podcast OSIS ini masih berubah-ubah, feedback yang diberikan oleh pendengar podcast ini yaitu guna meningkatkan kualitas olahan suara podcast agar tetap stabil dan jernih. Tetapi dalam keseluruhan podcast OSIS ini masih dalam kategori yang dapat didengarkan dengan cukup baik.

\section{Kesimpulan}

Produksi Podcast di SMK Taruna Terpadu 1diproduksi dengan professional baik dengan sumberdaya manusia yang handal dibidang broadcasting. Podcast di SMK Taruna Terpadu 1 diproduksi dengan pra produski dan pasca produksi sehingga menghasilkan podcast yang baik.

\section{References}

1. Ardianto, Elvinaro, Lukiati Komala dan Siti Karlinah.. Komunikasi Massa. Bandung: Simbiosa Rekatama Media.2010

2. Bungin, Burhan. Sosiologi Komunikasi. Jakarta: Kencana Prenada Media Group.2015

3. Effendy, Onong Uchjana. Ilmu Komunikasi Teori dan Praktek. Bandung: PT. Remaja Rosdakarya.2003

4. Effendy, Onong Uchjana. Ilmu Teori dan Filsafat Komunikasi. Bandung: PT. Aditya Bakti.2008

5. Fadilah. 2017 https://jurnal.unpad.ac.id/kajian-jurnalisme/article/view/10562

6. Fadilah, Efi, Pandan Yudhapramesti \& Nindi Aristi. Podcast sebagai Alternatif Distribusi Konten Audio. http://jurnal.unpad.ac.id/kajianjurnalism.2017

7. Khairunisa, Khairunisa, et al. Strategi Program Magazine Program Khazanah Edisi Ramadhan 2019. Jurnal Ilmiah Komunikasi (JIKOM) STIKOM IMA, 2020, 12.01: 24-32

8. Latief, Rusman dan Yusiatie Utud 2017. Kreatif Siaran Televisi . Jakarta :Prenadamedia Group.

9. Meisyanti. Platform Digital Siaran Suara Berbasis On Demand. https://www.semanticscholar.org/paper/PLATFORM-DIGITAL-SIARAN-SUARA-BERBASIS-ONDEMAND-Meisyanti-Kencana/eb5b5d70cb7720c12fc0eb0d1faf19bfe9f99c14.2020

10. Rakhmat, Jalaludin. Metode Penelitian Komunikasi. Bandung: PT.Remaja Rosdakarya.2012

11. Salim, Agus. Teori \& Paradigma Penelitian Sosial. Yogyakarta: TiaraWacana.2006

12. Sendjaja, Sasa Djuarsa. Pengantar Komunikasi. Jakarta: Universitas Terbuka.2016

13. Sugiyono. Metode Penelitian Kuantitatif, Kualitatif, dan R\&D. Bandung: Alfabeta.2011

14. Oktua Tamba, Androw 2014. Peran Radio Heartline 94,4 Fm Dalam Meningkatkan Pengenalan Lingkungan Hidup Kepadawarga Kelurahan Sungai Pinang Dalam Kecamatansungai Pinang Kota SAMARINDA. http://ejournal.ilkom.fisipunmul.ac.id

15. Yin, Robert.K. Studi Kasus : Desain dan Metode. Jakarta : Radja Grafindo.2002

16. Yamaguchi, Cindy. What is Podcasting?.https://hilo.hawaii.edu/oct/itus/documents/Podcasting.pdf 